\title{
Unchanged interleukin 6 level of protein and energy restricted goats during late gestation: the role of elevated blood nitric oxide
}

\author{
Zhixiong He ${ }^{1,2}$, Zhiliang Tan ${ }^{1}$, Zhihong Sun ${ }^{3}$, Karen A Beauchemin ${ }^{4}$, Shaoxun Tang ${ }^{1}$, Chuanshe Zhou ${ }^{1}$, \\ Xuefeng Han ${ }^{1}$, Min Wang ${ }^{1}$ and Duanqin $\mathrm{Wu}^{1,2}$ \\ ${ }^{1}$ Key Laboratory of Agro-ecological Processes in Subtropical Region, Institute of Subtropical Agriculture, The Chinese Academy of Sciences, Changsha 410125 \\ People's Republic of China \\ ${ }^{2}$ Graduate University of the Chinese Academy of Sciences, Beijing 100049, People's Republic of China \\ ${ }^{3}$ College of Animal Sciences and Technology, Southwest University, Chongqing 400715, People's Republic of China \\ ${ }^{4}$ Lethbridge Research Centre, Agriculture and Agri-Food Canada, Lethbridge, Alberta T1J 4B1, Canada \\ (Correspondence should be addressed to Z Tan; Email: zltan@isa.ac.cn)
}

\begin{abstract}
Twelve pregnant goats were assigned to three dietary treatments during late gestation, namely control (C: metabolizable energy, $5.75 \mathrm{MJ} / \mathrm{kg}$; crude protein, $12 \cdot 6 \%$ and dry matter basis), $40 \%$ protein restricted (PR) and $40 \%$ energy restricted (ER), to examine the effects of nutrient restriction on the immune status of pregnant goats. Plasma was sampled on day 90,125 and 145 from pregnant goats to determine cytokine production (interleukin 2 (IL2), IL6) and tumor necrosis factor $\alpha(\mathrm{TNF} \alpha)$ ). Peripheral blood mononuclear cells were obtained on day 145 and activated by lipopolysaccharide to determine cytokine production, and then exposed (PR and ER) to sodium nitroprusside (SNP), a nitric oxide (NO) donor, or control to NG-nitro-L-arginine methyl ester hydrochloride (L-NAME), an NO synthase
\end{abstract}

inhibitor to explore the role of $\mathrm{NO}$ in regulating cytokine production. Plasma IL2, IL6 and TNF $\alpha$ were not altered during gestation, but $\mathrm{NO}$ was increased $(P<0 \cdot 05)$ at gestation day 145 for $\mathrm{PR}$ and ER. In vitro, compared with control, NO was lower for PR and ER $(P<0 \cdot 001)$, but IL6 was higher for PR $(P<0 \cdot 001)$ and ER $(P=0 \cdot 11)$. The addition of SNP decreased IL6 $(P<0 \cdot 001$, PR; $P=0 \cdot 12$, ER) in the malnourished group, and L-NAME increased $(P<0.001)$ IL6 in control compared to those treatments without SNP or L-NAME. The results indicate that plasma $\mathrm{NO}$ acted as a regulator of cytokine function exhibiting negative feedback to maintain steady plasma IL6 concentration in PR or ER goats during late gestation.

Journal of Endocrinology (2012) 213, 59-65

\section{Introduction}

It has been postulated that predisposition to some adult diseases, such as type 2 diabetes, cardiovascular diseases and syndrome $\mathrm{X}$, is associated with a low-fetal birth weight (Barker 1994). It has been also proposed that adverse fetal environments, such as suboptimal supply of maternal nutrients, lead to permanent alternation in fetal cognitive functions and greater prevalence of metabolic syndromes (He et al. 2009). Bloomfield et al. (2003) demonstrated that maternal nutritional restriction of protein and energy resulted in a temporary effect on fetal weight but enduring changes in hypothalamic-pituitary-adrenal axis function in sheep. Thus, maternal nutrition might have long-lasting impacts on the growth and development of offspring.

In China, the nutritional status of flocks and herds is greatly influenced by conditions of the growing season (Glindermann et al. 2009). Winter (i.e. dry season) is the reproductive season of goats and sheep in Inner Mongolia, the yet nutritive value of pasture can be sub-optimal during this time.
For example, neutral detergent fibre and lignin contents of pasture during winter are highest (68 and $12 \%$ of dry matter (DM) respectively (Wang et al. 1997)), while crude protein (CP) content is lowest (reduced from $14 \%$ in summer and autumn to $5 \%$ of DM in spring and winter (Wang et al. 1997)). Low nutritive value of consumed pasture in winter results in low DM intake (DMI), and consequently the supply of metabolizable energy (ME, $5.5 \mathrm{MJ} / \mathrm{kg}$ ) can be below the requirement for local breeds of pregnant goats and sheep (Wang et al. 1997).

Maternal protein and energy restriction of grazing ruminants in the dry season resulting from low nutritive value of pasture and low DMI have stimulated interest in studying the relationship between maternal nutrient restriction and physiological function of the fetus. To date, the study of fetal programming induced by maternal nutrient restriction has focused on the physiological function of the hypothalamic-pituitary-adrenal axis and the endocrine system in the offspring, such as hypothalamic-pituitary-adrenal dysfunction (Bloomfield et al. 2003), glucose intolerance 
(Langley et al. 1994), insulin resistance (Petry et al. 2001), elevated blood pressure (Ozaki et al. 2001) and vascular dysfunction (Holemans et al. 1999). However, few experiments have investigated the effects of maternal nutrient restriction on maternal immune, biochemical and physiological conditions, and how these conditions may affect fetal programming.

The objective of the current study was to investigate the effects of maternal protein and energy restriction on the immune function of goats in late gestation. Concentrations of cytokines and other immune mediators (interleukin 2 (IL2), IL6) and tumor necrosis factor $\alpha$ (TNF $\alpha)$ ) were measured as indices of immune function.

\section{Materials and Methods}

In vivo experiment

The experiment was conducted according to the Animal Care and the Use Guidelines of the Animal Care Committee, Institute of Subtropical Agriculture, The Chinese Academy of Sciences (Changsha, China).

Twenty-five pregnant (second parity) female goats (Liuyang Blacks, local breed) of similar age $(2 \cdot 0 \pm 0 \cdot 3$ years) and body weight $(20 \cdot 0 \pm 1 \cdot 0 \mathrm{~kg})$ before pregnancy were obtained from the Liuyang Black Goat Reproduction Centre (Liuyang, Hunan Province, China). The goats had previously been synchronized for estrus and artificially inseminated to ensure consistency of pregnancy date. During early (0-30 days) and mid-gestation (30-82 days), the pregnant goats remained at pasture, each goat receiving $300 \mathrm{~g}$ /day of concentrate. The concentrate contained (DM basis): $74 \cdot 0 \%$ corn meal, $20 \cdot 3 \%$ soybean meal, $1 \cdot 3 \%$ calcium bicarbonate, $1 \cdot 6 \%$ calcium carbonate, $0.8 \%$ sodium chloride and $2 \%$ mineral-vitamin premix. The concentrate supplied $11 \cdot 0 \mathrm{MJ} / \mathrm{kg} \mathrm{ME}$ and $15 \cdot 4 \% \mathrm{CP}$. Twelve goats carrying one kid (pregnancy examination by ultrasound at gestation day 60) were chosen as experimental subjects for the study. At day 83 of gestation, the goats were moved to an indoor facility with an average temperature of $24 \pm 1{ }^{\circ} \mathrm{C}$ and penned individually with free access to fresh water.

The experiment was a completely randomized design with 12 pregnant goats randomly allocated to one of three diets (four animals per group) at day 90 until parturition. The three diets were control diet (C: ME 9.34 MJ/kg, CP 12.5\%), protein restricted diet (PR, $60 \%$ of the $\mathrm{CP}$ supplied by the control group: ME $9 \cdot 28 \mathrm{MJ} / \mathrm{kg}, \mathrm{CP} 7 \cdot 5 \%$ ) and energy restricted (ER) diet $(60 \%$ of the energy supplied by the control group: ME 5.75 MJ/kg, CP 12.6\%). The ingredients and composition of the three diets are given in Table 1 . The control diet supplied 1.2 times the maintenance $\mathrm{ME}$ and $\mathrm{CP}$ requirement according to the Chinese feeding standards (Zhang \& Zhang 1998) for pregnant goats. The level of restriction was chosen to represent the typical protein or energy status of goats during the dry season in this area of
Table 1 Ingredients and composition of diets

\begin{tabular}{|c|c|c|c|}
\hline & & Treatmer & \\
\hline & $\begin{array}{r}\text { Control } \\
\text { group }\end{array}$ & PR & ER \\
\hline Ingredients (\% DM) & & & \\
\hline Maize stover & $60 \cdot 00$ & $60 \cdot 00$ & $60 \cdot 00$ \\
\hline Corn & $8 \cdot 58$ & $21 \cdot 11$ & $3 \cdot 60$ \\
\hline Soybean & $8 \cdot 11$ & $1 \cdot 28$ & $4 \cdot 78$ \\
\hline Whey & $0 \cdot 00$ & $0 \cdot 00$ & $2 \cdot 00$ \\
\hline Wheat bran & $2 \cdot 12$ & $2 \cdot 04$ & $2 \cdot 00$ \\
\hline Alfalfa meal & $0 \cdot 00$ & $0 \cdot 00$ & $20 \cdot 64$ \\
\hline Fat powder & $10 \cdot 53$ & $11 \cdot 60$ & $0 \cdot 00$ \\
\hline Corn gluten meal & $8 \cdot 56$ & $1 \cdot 58$ & $4 \cdot 80$ \\
\hline Calcium bicarbonate & $0 \cdot 25$ & $0 \cdot 72$ & $0 \cdot 61$ \\
\hline Calcium carbonate & $0 \cdot 75$ & $0 \cdot 56$ & $0 \cdot 47$ \\
\hline Sodium chloride & $0 \cdot 30$ & $0 \cdot 31$ & $0 \cdot 31$ \\
\hline Premix $^{a}$ & $0 \cdot 80$ & $0 \cdot 80$ & $0 \cdot 80$ \\
\hline Nutrient content ${ }^{b}$ & & & \\
\hline $\mathrm{ME}(\mathrm{MJ} / \mathrm{kg})$ & $9 \cdot 34$ & $9 \cdot 28$ & $5 \cdot 75$ \\
\hline $\mathrm{CP}(\%)$ & $12 \cdot 5$ & $7 \cdot 5$ & $12 \cdot 6$ \\
\hline Ca $(\%)$ & $0 \cdot 518$ & $0 \cdot 518$ & $0 \cdot 518$ \\
\hline $\mathrm{P}(\%)$ & $0 \cdot 34$ & $0 \cdot 34$ & $0 \cdot 34$ \\
\hline
\end{tabular}

$P R$, protein restricted group; $E R$, energy restricted group.

${ }^{a}$ Contained per kilogram: $119 \mathrm{~g} \mathrm{MgSO}_{4} \cdot \mathrm{H}_{2} \mathrm{O}, 2.5 \mathrm{~g} \quad \mathrm{FeSO}_{4} \cdot 7 \mathrm{H}_{2} \mathrm{O}$, $0 \cdot 8 \mathrm{~g} \mathrm{CuSO}_{4} \cdot 5 \mathrm{H}_{2} \mathrm{O}, 3 \mathrm{~g} \mathrm{MnSO}_{4} \cdot \mathrm{H}_{2} \mathrm{O}, 5 \mathrm{~g} \mathrm{ZnSO}_{4} \cdot \mathrm{H}_{2} \mathrm{O}, 10 \mathrm{mg} \mathrm{Na} \mathrm{SeO}_{3}$, $40 \mathrm{mg} \mathrm{KI}, 30 \mathrm{mg} \mathrm{CoCl} \cdot 6 \mathrm{H}_{2} \mathrm{O}, 95000$ IU vitamin A, 17500 IU vitamin D and $18000 \mathrm{IU}$ vitamin $\mathrm{E}$.

${ }^{\mathrm{b}} \mathrm{CP}$, $\mathrm{Ca}$ and $\mathrm{P}$ were determined values, and ME was calculated according to the data of Zhang \& Zhang (1998).

China. The goats were offered the experimental diets 1 week before starting the study (day 83) and were allowed to feed ad libitum, to allow them time to adapt. The amounts offered were $1-1 \cdot 1 \mathrm{~kg} /$ day from day 90 to 120 and $1 \cdot 1-1 \cdot 2 \mathrm{~kg} /$ day from day 120 to 145 . Feed was offered in two equal amounts at 0800 and $1800 \mathrm{~h}$ daily and feed offered and orts were recorded daily to measure feed intake. All animals were weighed before the morning feeding on day 90, 100, 120 and 140 of gestation, and had free access to water.

Blood samples were collected using sterile hypodermic syringes from the jugular vein of each goat on day 90, 125 and 145 of gestation into sterile tubes treated with sodium heparin or EDTA. The samples were centrifuged at $3000 \mathrm{~g}$ for $15 \mathrm{~min}$, and plasma were separated into aliquots and stored at $-20{ }^{\circ} \mathrm{C}$ for subsequent analysis.

\section{In vitro experiments}

Culture of peripheral blood mononuclear cells The first assay was conducted to determine the effects of nutritional restriction of the goats on nitric oxide (NO), IL2, IL6 and TNF $\alpha$ secreted by peripheral blood mononuclear cells (PBMCs). The experiment was a completely randomized design using blood samples from day 145 from three goats for each of the dietary treatments (control, PR and ER). Blood samples preserved in EDTA were diluted in Hanks solution. The PBMCs were separated by density gradient centrifugation 
at $2000 \mathrm{~g}$ for $15 \mathrm{~min}$ using lymphocyte separation media (Mediatec Inc., Herndon, VA, USA). The PBMCs were lifted from the interface and washed three times in RPMI 1640 medium (Invitrogen). The cells were plated at $1 \times 10^{6}$ cells $/ \mathrm{ml}$ in RPMI 1640 medium supplemented with 10\% fetal bovine serum, $100 \mu \mathrm{g} / \mathrm{ml}$ streptomycin and $100 \mathrm{U} / \mathrm{ml}$ penicillin, then treated with lipopolysaccharide (LPS; Escherichia coli, 0111:B4; Sigma). The LPS concentration was adjusted to $20 \mathrm{ng} / \mathrm{ml}$ according to previous study (Anstead et al. 2003). Later, the cells were incubated at $37^{\circ} \mathrm{C}$ in $5 \% \mathrm{CO}_{2}$. Suspensions were collected at 4 and $48 \mathrm{~h}$ in duplicate.

A subsequent assay was conducted to determine if $\mathrm{NO}$ displays negative feedback regulation on IL2, IL6 and TNF $\alpha$ secreted by PBMCs from goats affected by nutritional restriction. The assay was conducted as a completely randomized design using PBMCs from three goats per diet, with and without $\mathrm{NO}$ inhibitor in the case of control goats or with and without exogenous $\mathrm{NO}$ in the case of PR and ER goats. The inhibitor was NG-nitro-L-arginine methyl ester hydrochloride (L-NAME; Cayman Chemical Company, Ann Arbor, MI, USA). The L-NAME was dissolved in DMSO (Sigma) to make a stock solution of $5 \mathrm{mg} / \mathrm{ml}$, from which final concentrations were prepared. Sodium nitroprusside (SNP; Beyotime, Haimen, Jiangsu, China) was directly dissolved in PBS. For control goats, L-NAME was added to the culture $15 \mathrm{~min}$ after the addition of LPS $(20 \mathrm{ng} / \mathrm{ml})$ to a concentration of $1 \mathrm{mM}$. For the PR and ER goats, SNP was added to the LPS-stimulated PBMC to a concentration of $0.1 \mathrm{mM}$. At the same time, appropriate concentrations of DMSO or PBS were added to cell suspensions as controls for L-NAME or SNP respectively. After $4 \mathrm{~h}$, the suspensions were collected and assayed for NO, IL2, IL6 and TNF $\alpha$.

\section{Measurement of NO, IL2, IL6 and TNF $\alpha$ The NO} production of plasma and PBMC suspensions was determined colorimetrically with a u.v. spectrophotometer (8500 II; Thermo Electron Corporation, Rochester, NY, USA). The assay kits were purchased from Nanjing Jiancheng Bioengineering Institute (Nanjing, Jiangsu, China).

The IL2, IL6 and TNF $\alpha$ concentration of plasma and PBMC cell suspension were determined using ELISA kits (R\&D System, Minneapolis, MN, USA). Briefly, 96 well plates coated with anti-goat IL2, IL6 and TNF $\alpha$ monoclonal antibodies were incubated for $30 \mathrm{~min}$ at $37^{\circ} \mathrm{C}$ after plasma and cell suspension samples were added. Then the wells were washed five times using washing buffers and probed with HRP-tagged anti-goat IL2, IL6 and TNF $\alpha$ antibodies for $30 \mathrm{~min}$ at $37^{\circ} \mathrm{C}$. Later, the wells were washed five times using the washing buffers and further added with chromogen solution. The plates were incubated for $10 \mathrm{~min}$ at $37^{\circ} \mathrm{C}$ in the dark, and the reaction was stopped by adding $1 \mathrm{M} \mathrm{H}_{2} \mathrm{SO}_{4}$. The optical density was measured at $450 \mathrm{~nm}$ by microplate reader (Labsystems, Helsinki, Finland). The intra- and interassay coefficient of variations determined NO, IL2, IL6 and $\mathrm{TNF} \alpha$ according to the above-mentioned procedures were all below $10 \%$.

\section{Statistical analysis}

For the in vivo experiment, data for body weight and cytokine analysis of plasma samples were analysed using the PROC MIXED procedure of SAS 9.2 (2002; SAS Inc., Cary, NC, USA). The model included the fixed effect of diet and $\operatorname{diet} X$ day, with day considered a repeated effect. Differences between diets were tested using a least square difference test using the Kenward-Roger adjustment. For the in vitro experiment the cytokine analysis was analysed by time ( 4 and $48 \mathrm{~h}$ ) using the proc mixed procedure using a model that included the fixed effect of diet, replication and $\operatorname{diet} \times$ replication. The PBMC suspensions were analysed by diet (control, PR and ER) using the PROC MIXED procedure with a model that included the fixed effect of treatment (control, LPS alone or LPS + L-NAME; PR and ER, LPS alone or LPS +SNP), replication, and their two-way interaction. Least square means are presented in the text and statistical significance was declared at $P \leq 0.05$ with trends discussed at $P \leq 0 \cdot 15$.

\section{Results}

\section{Feed intake and body weight}

Daily feed intake was not affected by protein or energy restriction during late gestation (control, $1027 \pm 24 \mathrm{~g}$; PR, $1025 \pm 15$ g; ER, $1028 \pm 22$ g). Daily CP intake in PR and ME intake in ER were decreased $40 \cdot 0 \%(76 \cdot 9 \pm 1 \cdot 19$ vs $128 \cdot 4 \pm 3 \cdot 06 \mathrm{~g})$ and $38 \cdot 3 \%(5 \cdot 9 \pm 0 \cdot 13$ vs $9 \cdot 6 \pm 0 \cdot 23 \mathrm{MJ}$ respectively) compared to the control group. Body weight increased from an average of $22 \cdot 2 \pm 1 \cdot 46 \mathrm{~kg}$ at day 90 of gestation to $26 \cdot 7 \pm 1 \cdot 78 \mathrm{~kg}$ at day 140 , but body weight was not affected $(P=0 \cdot 91)$ by diet (Fig. 1$)$.

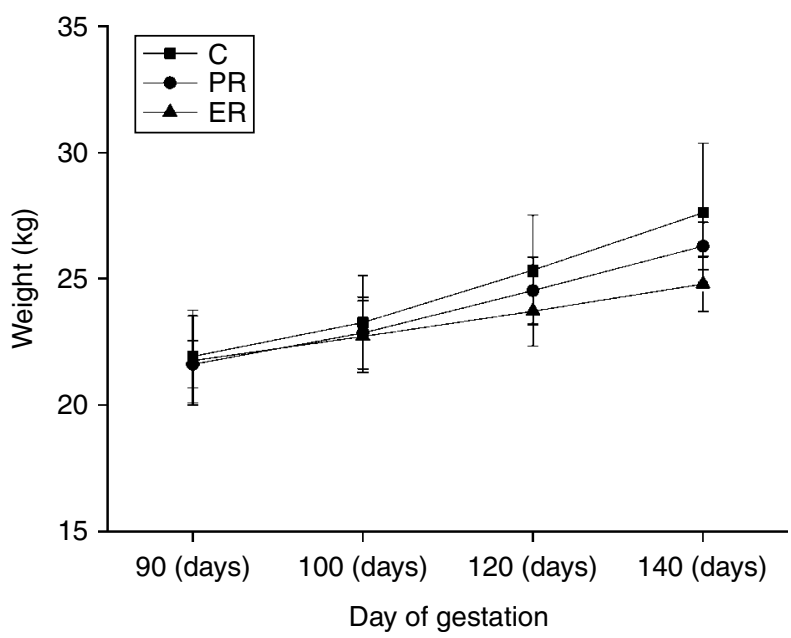

Figure 1 Body weight change of pregnant goats fed three diets. Control, C; protein restricted group, PR; energy restricted group, ER. No difference among diets at day $90,100,120$ and $140(P>0 \cdot 05)$. 
Nutrient restriction promoted the release of plasma NO, but did not alter IL2, IL6 and TNF $\alpha$ concentrations

Pregnant goats subjected to ER or PR had higher plasma concentrations of $\mathrm{NO}(P<0 \cdot 05)$ than control goats by day 145 (Fig. 2A). However, plasma IL2, IL6 and $\mathrm{TNF} \alpha$ concentrations were unaffected by protein and energy restriction from day 90 to 145 of gestation (Fig. 2B, C and D).

PBMCs from nutrient restricted goats produced less NO and altered the pro-inflammatory response to LPS

At both time points, PBMCs from PR and ER goats produced less NO than those from control goats $(P<0 \cdot 001)$ after stimulation with LPS (Fig. 3A). After $4 \mathrm{~h}$ of stimulation, the NO concentration produced by PBMCs from the control group was almost 13 and four times more than those from PR and ER groups respectively. By $48 \mathrm{~h}$, the NO concentration produced by PBMCs from control goats was almost four and 13 times more than those from $\mathrm{PR}$ and ER groups respectively.

At both 4 and $48 \mathrm{~h}$, LPS-stimulated PBMCs from ER produced $(P<0.05)$ more IL2 than PBMCs from control (Fig. 2B). Protein restriction, however, had no effect on IL2. For IL6, the concentration secreted by LPS-stimulated PBMCs from $\mathrm{PR}$ goats was lower $(P=0 \cdot 02)$ than from control goats at $4 \mathrm{~h}$, but it was substantially higher $(P<0 \cdot 001)$ at $48 \mathrm{~h}$ (Fig. 3C). Concentration of IL6 was only higher $(P=0 \cdot 01)$ for ER compared to control at $4 \mathrm{~h}$. For TNF $\alpha$, LPS-stimulated PBMCs were higher $(P<0 \cdot 001)$ for PR compared to control at both time points, but there was no difference between control and ER (Fig. 3D).
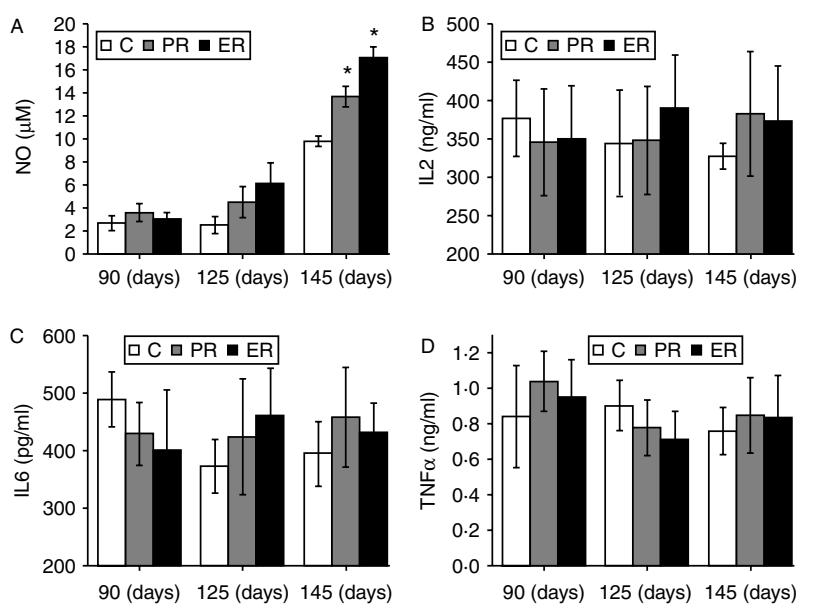

Figure 2 Effects of protein and energy restriction on plasma (A) NO, (B) IL2, (C) IL6 and (D) TNF $\alpha$ concentration at gestation day 90, 125 and 145 in pregnant goats. ${ }^{*} P<0 \cdot 05$, ER and PR compared with $C$. Control, C; protein restricted group, PR; energy restricted group, ER.
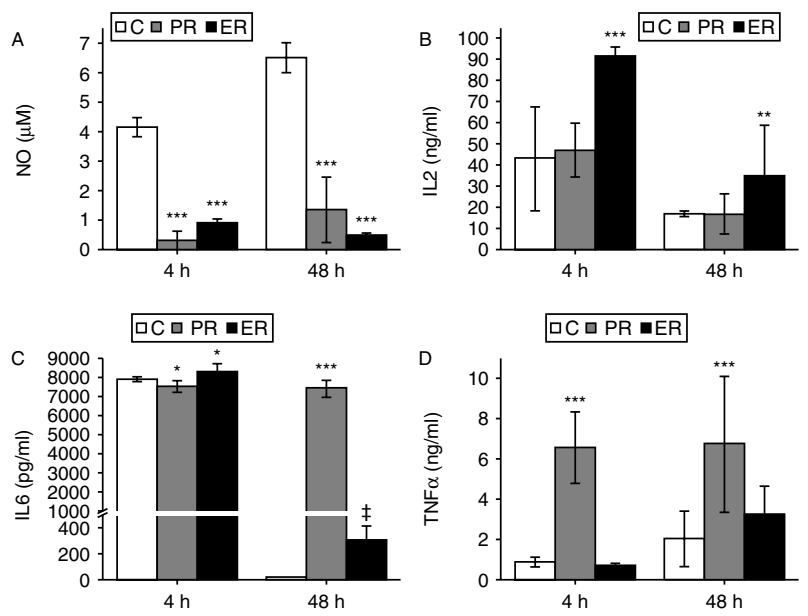

Figure 3 Effects of protein and energy restriction on secretion of (A) NO, (B) IL2, (C) IL6 and (D) TNF $\alpha$ by PBMCs from goats on day 145 of gestation stimulated with LPS and incubated for 4 and $48 \mathrm{~h}$. The cells were obtained from three goats per group, with six replicates of every sample. ${ }^{*} P<0 \cdot 05, * * P<0 \cdot 01,{ }^{* * *} P<0 \cdot 001$ and ${ }^{\ddagger} P<0 \cdot 10$; ER and PR compared with C. Control, C; protein restricted group, $\mathrm{PR}$; energy restricted group, $\mathrm{ER}$.

Exogenous NO resulted in less IL6 production in PBMCs from $P R$ and ER goats

With SNP addition, NO concentration in PBMCs from PR and ER groups increased 316- and 98-fold, respectively (Figs 4A and 5A). For PBMCs from the PR goats, addition of SNP had no effect on IL2, but decreased $(P<0 \cdot 001)$ IL6 and TNF $\alpha$ (Fig. 4B, C and D). For PBMCs from the ER goats, addition of SNP decreased $(P<0 \cdot 001)$ IL2, tended $(P=0 \cdot 12)$ to decrease IL6 and increased $(P<0 \cdot 001)$ TNF $\alpha$ (Fig. 5B, C and D).

Inhibition of NO synthase reduced IL6 production in PBMCs from well-nourished goats

When L-NAME was added to the media of LPS-stimulated PBMCs from well-nourished goats, $\mathrm{NO}$ accumulation at $4 \mathrm{~h}$ decreased $(P<0 \cdot 001) 7 \cdot 2$-fold (Fig. 6A). The inhibition of NO production increased $(P<0 \cdot 001)$ IL6 by $74 \%$ (Fig. 6C) and there were numerical increases $(P=0.06)$ of TNF $\alpha$ (Fig. 6D), but not $(P=0 \cdot 35)$ IL2 (Fig. 6B).

\section{Discussion}

A $40 \%$ protein or energy restriction for 2 months during late gestation of goats was chosen as the animal model to explore the effects of malnutrition on maternal cytokine production. Restriction of energy or protein promoted the release of plasma NO, but did not alter IL2, IL6 and TNF $\alpha$ concentrations. In contrast to these results, rats fed a low-protein $(2 \%)$ diet for 14 days showed increases in plasma 

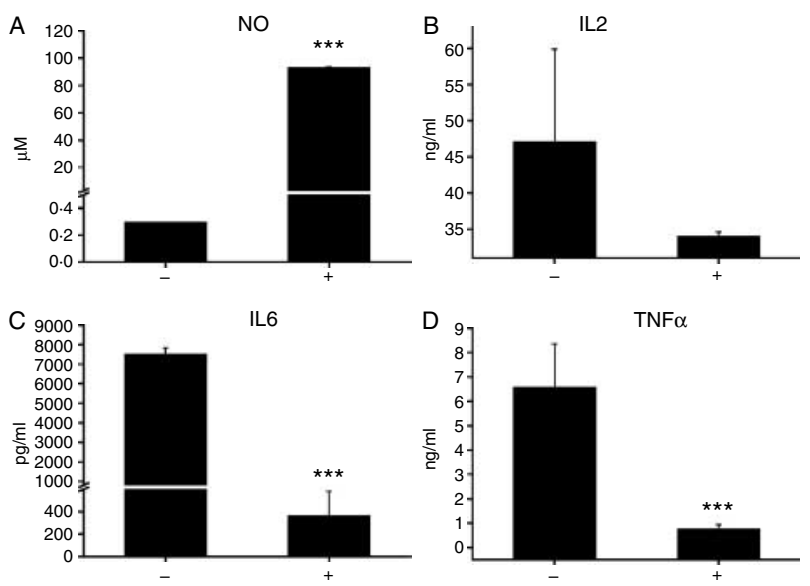

Figure 4 Effects of exogenous $\mathrm{NO}$ on concentrations of (A) NO, (B) IL2, (C) IL6 and (D) TNF $\alpha$ released by PBMCs collected from PR goats on day 145 of gestation. Cultures of cells were supplemented with exogenous NO using SNP. The PBMCs were stimulated with LPS alone $(-)$ or LPS + SNP $(+)$ for $4 \mathrm{~h}$ of incubation. The PBMCs were obtained from three goats and six replicates were conducted. $* * * P<0 \cdot 0001$; effects of SNP addition.

pro-inflammatory cytokines (including $\mathrm{TNF} \alpha$ and IL6) compared to rats fed a $20 \%$ protein diet (Ling et al. 2004). These conflicting results may indicate that the extent of nutrient restriction might have a significant effect on cytokine production. While the level of restriction imposed in our study was about $40 \%$ below the protein and/or energy requirements of the goats, body weight was not affected, indicating that the level of restriction was moderate compared to the acute restriction level imposed by Ling et al. (2004). The lack of change in body weight might be due to the reduction of maintenance requirement of energy in PR or ER pregnant goats (Ryan et al. 1993). In previous experiments, there have been variable inflammatory immune responses to malnutrition. Decreased plasma TNF $\alpha$ production has been reported in rodent models of protein-energy malnutrition (Chan et al. 1996, Schaffer et al. 1997, Anstead et al. 2001), but increased plasma IL6 concentration has been observed in malnourished patients (Malave et al. 1998, Johann-Liang et al. 2000, de Martino et al. 2000). In addition, maternal dietary protein restriction decreased NO synthase (NOS) in endometrium and placenta of pigs during early gestation (Wu et al. 1998). These varying responses may indicate that variation of immune response to malnutrition depends on the animal model and duration and extent of nutrient restriction.

The in vitro model further explored the effects of dietary restriction on the cytokines produced by PBMCs. The PBMCs from both ER and PR nutrient goats produced less NO than control goats, which generally increased the proinflammatory response to LPS. Our results are in agreement with Anstead et al. (2003) who demonstrated that multinutrient undernutrition dysregulates the resident macrophage pro-inflammatory cytokine network in mice. The PBMCs separated from blood contain lymphocytes and monocytes, which mediate host defense of innate immunity when these cells are recognized pathogens, such as LPS (Beutler 1999). The production of pro-inflammatory cytokines, such as IL2, IL6 and IL10, is regulated by the transcription factor of NFKB (Blackwell \& Christman 1997, Ghosh et al. 1998), which has been shown to be dysregulated by multi-nutrient undernutrition (Anstead et al. 2003). In a previous study, LPS-stimulated PBMCs from severely malnourished children were found to produce less TNF $\alpha$ (Doherty et al. 1994), which is not consistent with the higher concentrations of TNF $\alpha$ observed for PR goats in our study (Fig. 3D). These results indicate that other regulatory factors may play an important role in $\mathrm{TNF} \alpha$ production during gestation.

The current results demonstrated that there was a discrepancy between the plasma NO and the NO released by PBMCs. The results suggested that inflammatory cells were not the source of the increased plasma NO in late pregnant goats under the condition of protein or energy restriction. For example, vascular endothelial cells can produce NO. Simultaneously, the conflicting results for cytokine production in relation to $\mathrm{NO}$ concentration in vivo and in vitro may indicate that there are other regulation factors in pregnant goats under the conditions of protein and energy restriction. It is possible that the cytokine network was regulated through the increasing NO concentration observed during protein and energy restriction in pregnant goats. Further, we confirmed that the negative feedback function of NO (Connelly et al. 2001) regulated the production of IL2 and IL6 in these goats.

In the subsequent in vitro experiments, PBMCs, representing lymphocytes and macrophages, were used to study the relationship between $\mathrm{NO}$ and cytokine production through
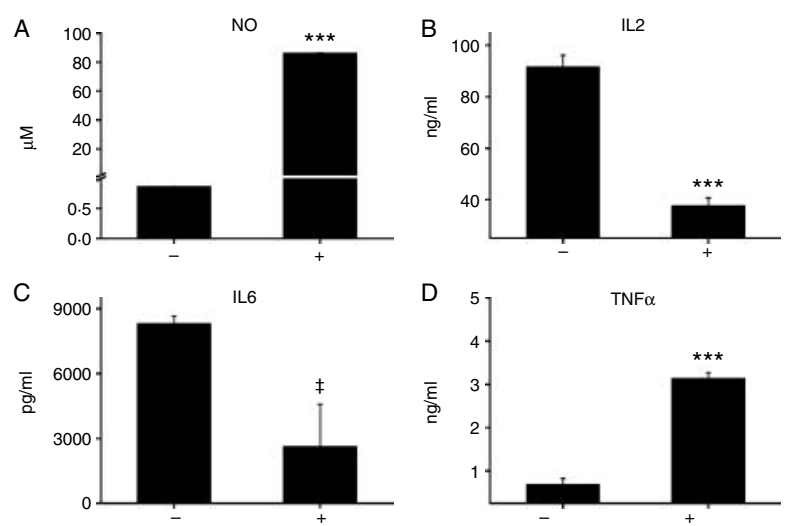

Figure 5 Effects of exogenous $\mathrm{NO}$ on concentrations of (A) NO, (B) IL2, (C) IL6 and (D) TNF $\alpha$ released by PBMCs collected from ER goats on day 145 of gestation. Cultures of cells were supplemented with NO by adding SNP. The PBMCs stimulated with LPS alone (-) or LPS + SNP $(+)$ for $4 \mathrm{~h}$ of incubation. The PBMCs were obtained from three goats and six replicates were conducted. ${ }^{* * *} P<0 \cdot 0001$ and ${ }^{\ddagger} P<0 \cdot 10$; effects of SNP addition. 


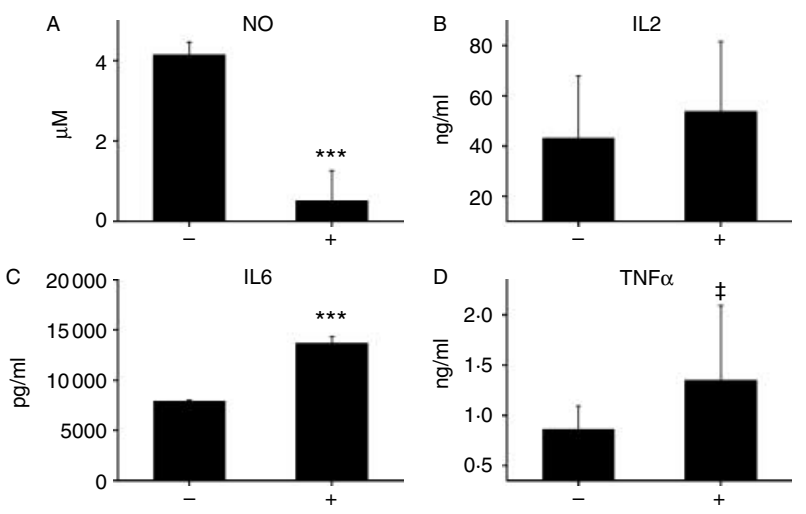

Figure 6 Effects of NOS inhibition on (A) NO, (B) IL2, (C) IL6 and (D) TNF $\alpha$ concentrations released by PBMCs collected from wellnourished goats on day 145 of gestation. The NOS was inhibited using L-NAME. The PBMCs were stimulated with LPS alone $(-)$ or LPS + L-NAME $(+)$ for $4 \mathrm{~h}$ of incubation. The PBMCs were obtained from three goats and six replicates were conducted. ${ }^{* * *} P<0 \cdot 001$ and ${ }^{\ddagger} P<0 \cdot 10$; effects of L-NAME addition.

the addition of SNP and L-NAME to PBMC culture media. The increased exogenous NO concentration of PBMCs collected from PR and ER goats with SNP added to the culture medium and corresponding declines in IL2 (only for ER) and IL6 concentrations confirm the negative feedback role of NO in goats. Additionally, the higher IL6 concentration with addition of L-NAME to the culture medium of PBMCs collected from control goats further confirms the role of NO in regulating cytokines, and in particular IL6. It follows that plasma cytokine concentration (especially IL6) in malnourished pregnant goats remained constant throughout late gestation by elevated NO production, which downregulated the increased cytokine production released by PBMC. However, with the limitation of animal numbers in the current study, the important finding on negative feedback function of NO regulating the cytokine production needs more experiments to testify for malnourished pregnant ruminants.

In this study, we found that the biosynthesis of $\mathrm{NO}$ increased with time of gestation in late pregnant goats. Similarly, biosynthesis of NO increased in rats and sheep throughout gestation, but NO status in human pregnancy is inconsistent according to the review of Sladek et al. (1997). $\mathrm{NO}$ is endogenously produced from L-arginine and is catalysed by two types of NOS: constitutive NOS and inducible NOS (iNOS). Under normal physiological conditions, only a small amount of $\mathrm{NO}$ is produced by constitutive endothelial NOS and neuronal NOS and it has several biological functions, including the regulation of blood vessel tone and neurotransmission. Increased $\mathrm{NO}$ in late gestation has been shown to regulate the uterine and fetoplacental blood flow, and it is involved in uterine quiescence prior to parturition (Sladek et al. 1997). The large amounts of NO produced by iNOS are known to be responsible for the inflammation, vasodilation and hypotension observed in septic shock and cancer metastasis (Bogdan 2001, Guzik et al. 2003, Lange et al. 2009, Luiking et al. 2010). Additionally, large amounts of NO are toxic and pro-inflammatory, and are thought to play a central role in endotoxin-induced tissue damage (Kmiec 2001). High output of NO increases the risk of susceptibility to human disease because of NO-mediated cytotoxicity (Kroncke et al. 1998). Localized concentration of NO (approaching 4-5 $\mu \mathrm{M}$ ) in a site of inflammation is toxic to all cells in the vicinity (Marletta \& Spiering 2003). In the current study, plasma NO concentrations of $40 \% \mathrm{PR}$ and ER goats were increased when compared with control goats at day 145 of gestation. Increased plasma NO production in nutrient restriction groups could result in a detrimental impact on the uterus and placenta, thereby retarding placental and fetal growth. Similarly, protein or energy restriction might increase the plasma NO for human pregnancies. Given the cytotoxicity of high NO concentration, it would be interesting to further investigate whether the elevated $\mathrm{NO}$ production in the malnourished mother plays a role in fetal programming.

In summary, protein or energy restriction increased plasma NO production but did not affect the concentration of plasma IL2, IL6 and TNF $\alpha$ in pregnant goats during late gestation. Further in vitro studies using PBMCs from these goats demonstrated that protein or energy restriction decreased NO production but generally increased the secretion of IL2 and IL6. Finally, plasma NO was confirmed to act as a negative feedback regulator for IL2 and especially IL6 production released by lymphocytes and macrophages. Together, these findings indicate that malnutrition of pregnant goats during late gestation caused elevated NO levels in plasma, which inhibited cytokine production, particularly that of IL6. Consequently, cytokine concentrations in plasma remain relatively unchanged as a result of malnutrition of goats in late gestation.

\section{Declaration of interest}

The authors declare that there is no conflict of interest that could be perceived as prejudicing the impartiality of the research reported.

\section{Funding}

This study was financially supported by CAS Visiting Professorship for Senior International Scientists (grant number 2010T2S13) and CAS/SAFEA International Partnership Program for Creative Research Teams (grant number KZCX2-YW-T07).

\section{Acknowledgements}

We acknowledge the participation of Prof. Zhiliang Tan for direction of the experimental design, Drs Zhihong Sun, Shaoxun Tang, Xuefeng Han and Duanqing Wu for assistance with analyses, Prof. Karen Beauchemin for data analyses and paper revision and Chuanshe Zhou and Ming Wang for guidance with the animal experiments and laboratory analyses. 


\section{References}

Anstead GM, Chandrasekar B, Zhao WG, Yang J, Perez LE \& Melby PC 2001 Malnutrition alters the innate immune response and increases early visceralization following Leishmania donovani infection. Infection and Immunity 69 4709-4718. (doi:10.1128/IAI.69.8.4709-4718.2001)

Anstead GM, Chandrasekar B, Zhang Q \& Melby PC 2003 Multinutrient undernutrition dysregulates the resident macrophage proinflammatory cytokine network, nuclear factor-kappa B activation, and nitric oxide production. Journal of Leukocyte Biology 74 982-991. (doi:10.1189/jlb. 0203064)

Barker DJP 1994 Programming the baby. In Mothers, babies and disease in later life. London: BMJ Publishing Group.

Beutler BA 1999 The role of tumor necrosis factor in health and disease. Journal of Rheumatology 26 16-21.

Blackwell TS \& Christman JW 1997 The role of nuclear factor-kappa B in cytokine gene regulation. American Journal of Respiratory Cell and Molecular Biology 17 3-9.

Bloomfield FH, Oliver MH, Giannoulias CD, Gluckman PD, Harding JE \& Challis JRG 2003 Brief undernutrition in late-gestation sheep programs the hypothalamic-pituitary-adrenal axis in adult offspring. Endocrinology 144 2933-2940. (doi:10.1210/en.2003-0189)

Bogdan C 2001 Nitric oxide and the immune response. Nature Immunology 2 907-916. (doi:10.1038/ni1001-907)

Chan J, Tian Y, Tanaka KE, Tsang MS, Yu KM, Salgame P, Carroll D, Kress Y, Teitelbaum R \& Bloom BR 1996 Effects of protein calorie malnutrition on tuberculosis in mice. PNAS 93 14857-14861. (doi:10.1073/pnas.93.25. 14857)

Connelly L, Palacios-Callender M, Ameixa C, Moncada S \& Hobbs AJ 2001 Biphasic regulation of NF-kappa B activity underlies the pro- and antiinflammatory actions of nitric oxide. Journal of Immunology 166 3873-3881.

Doherty JF, Golden MHN, Remick DG \& Griffin GE 1994 Production of interleukin-6 and tumor-necrosis-factor-alpha in-vitro is reduced in wholeblood of severely malnourished children. Clinical Science 86 347-351.

Ghosh S, May MJ \& Kopp EB 1998 NF-kappa B and rel proteins: evolutionarily conserved mediators of immune responses. Annual Review of Immunology 16 225-260. (doi:10.1146/annurev.immunol.16.1.225)

Glindermann T, Wang C, Tas BM, Schiborra A, Gierus M, Taube F \& Susenbeth A 2009 Impact of grazing intensity on herbage intake, composition, and digestibility and on live weight gain of sheep on the Inner Mongolian steppe. Livestock Science 124 142-147. (doi:10.1016/j.livsci. 2009.01.007)

Guzik TJ, Korbut R \& Adamek-Guzik T 2003 Nitric oxide and superoxide in inflammation and immune regulation. Journal of Physiology and Pharmacology 54 469-487.

He ZX, Sun ZH, Liu SM, Zhang QL \& Tan ZL 2009 Effects of early malnutrition on mental system, metabolic syndrome, immunity and the gastrointestinal tract. Journal of Veterinary Medical Science 71 1143-1150. (doi:10.1292/jvms.71.1143)

Holemans K, Gerber R, Meurrens K, De Clerck F, Poston L \& Van Assche FA 1999 Maternal food restriction in the second half of pregnancy affects vascular function but not blood pressure of rat female offspring. British Journal of Nutrition 81 73-80. (doi:10.1017/S0007114599000173)

Johann-Liang R, O’Neill L, Cervia J, Haller I, Giunta Y, Licholai T \& Noel GJ 2000 Energy balance, viral burden, insulin-like growth factor-1, interleukin-6 and growth impairment in children infected with human immunodeficiency virus. AIDS 14 683-690. (doi:10.1097/00002030200004140-00007)

Kmiec Z 2001 Cooperation of liver cells in health and disease. Advances in Anatomy, Embryology, and Cell Biology 161 III-XIII. 1-151.

Kroncke KD, Fehsel K \& Kolb-Bachofen V 1998 Inducible nitric oxide synthase in human diseases. Clinical and Experimental Immunology 113 147-156. (doi:10.1046/j.1365-2249.1998.00648.x)
Lange M, Enkhbaatar P, Nakano Y \& Traber DL 2009 Role of nitric oxide in shock: the large animal perspective. Frontiers in Bioscience 14 1979-1989. (doi:10.2741/3357)

Langley SC, Browne RF \& Jackson AA 1994 Altered glucose-tolerance in rats exposed to maternal low-protein diets in-utero. Comparative Biochemistry and Physiology. Physiology 109 223-229. (doi:10.1016/0300-9629(94)90124-4)

Ling PR, Smith RJ, Kie S, Boyce P \& Bistrian BR 2004 Effects of protein malnutrition on IL-6-mediated signaling in the liver and the systemic acute-phase response in rats. American Journal of Physiology. Regulatory, Integrative and Comparative Physiology 287 R801-R808. (doi:10.1152/ ajpregu.00715.2003)

Luiking YC, Engelen M \& Deutz NEP 2010 Regulation of nitric oxide production in health and disease. Current Opinion in Clinical Nutrition and Metabolic Care 13 97-104. (doi:10.1097/MCO.0b013e328332f99d)

Malave I, Vethencourt MA, Chacon R, Quinones D, Rebrij C \& Bolivar G 1998 Production of interleukin-6 in cultures of peripheral blood mononuclear cells from children with primary protein-calorie malnutrition and from eutrophic controls. Annals of Nutrition and Metabolism 42 266-273. (doi:10.1159/000012743)

Marletta MA \& Spiering MM 2003 Trace elements and nitric oxide function. Journal of Nutrition 133 1431S-1433S.

de Martino M, Galli L, Chiarelli F, Verrotti A, Rossi ME, Bindi G, Galluzzi F, Salti R \& Vierucci A 2000 Interleukin-6 release by cultured peripheral blood mononuclear cells inversely correlates with height velocity, bone age, insulin-like growth factor-I, and insulin-like growth factor binding protein3 serum levels in children with perinatal HIV-1 infection. Clinical Immunology 94 212-218. (doi:10.1006/clim.2000.4838)

Ozaki T, Nishina H, Hanson MA \& Poston L 2001 Dietary restriction in pregnant rats causes gender-related hypertension and vascular dysfunction in offspring. Journal of Physiology 530 141-152. (doi:10.1111/j.1469-7793. $2001.0141 \mathrm{~m} . \mathrm{x})$

Petry CJ, Dorling MW, Pawlak DB, Ozanne SE \& Hales CN 2001 Diabetes in old male offspring of rat dams fed a reduced protein diet. International Journal of Experimental Diabetes Research 2 139-143. (doi:10.1155/EDR. 2001.139)

Ryan WJ, Williams IH \& Moir RJ 1993 Compensatory growth in sheep and cattle. I. Growth pattern and feed intake. Australian Journal of Agricultural Research 44 1609-1921. (doi:10.1071/AR9931609)

Schaffer MR, Tantry U, Ahrendt GM, Wasserkrug HL \& Barbul A 1997 Acute protein-calorie malnutrition impairs wound healing: a possible role of decreased wound nitric oxide synthesis. Journal of the American College of Surgeons 184 37-43.

Sladek SM, Magness RR \& Conrad KP 1997 Nitric oxide and pregnancy. American Journal of Physiology. Regulatory, Integrative and Comparative Physiology 272 R441-R463.

Wang HR, Feng ZC, Lu DX, Ren JK, Li HR, Peter DW, Lindsay J \& Purser DB 1997 Effects of seasonal nutritive changes with forage on dietary intake and growth performance of grazing goats (in chinese). Inner Mongolian Journal of Animal Sciences and Production S1 143-150.

Wu GY, Pond WG, Flynn SP, Ott TL \& Bazer FW 1998 Maternal dietary protein deficiency decreases nitric oxide synthase and ornithine decarboxylase activities in placenta and endometrium of pigs during early gestation. Journal of Nutrition 128 2395-2402.

Zhang HF \& Zhang ZY 1998 Feeding standard of goats. In Animal nutrition parameters and feeding standard (in Chinese). pp 350-352 Beijing: China Agriculture Press.

Received in final form 16 January 2012

Accepted 23 January 2012

Made available online as an Accepted Preprint 23 January 2012 